\title{
INFLUENCE OF THE Milling CUTTER DiAMETER ON THE CUTTING TOOL LIFE WHEN MACHINING INCONEL 718
}

\author{
Miroslav Zetek, Vojtěch Vozár, Tomáš Bakša \& Ivana Zetková
}
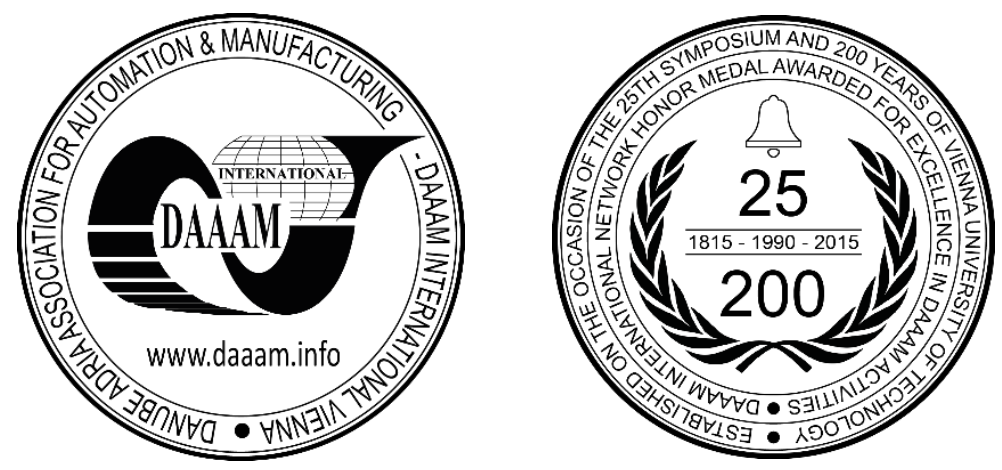

This Publication has to be referred as: Zetek, M[iroslav]; Vozar, V[ojtech]; Baksa, T[omas] \& Zetkova, I[vana] (2017). Influence of the Milling Cutter Diameter on the Cutting Tool Life when Machining Inconel 718, Proceedings of the 28th DAAAM International Symposium, pp.0417-0422, B. Katalinic (Ed.), Published by DAAAM International, ISBN 9783-902734-11-2, ISSN 1726-9679, Vienna, Austria DOI: $10.2507 / 28$ th.daaam.proceedings.058

\begin{abstract}
Indexable multi-insert milling cutters are the most economical and productive face milling tools. In case of the Inconel alloy machining there are some specific cutting conditions and strategies that influence cutting tool life and surface quality. When the indexable cutting inserts are used, it is recommended to use always down milling and avoid positioning cutter on-centre. For the tool entry is recommended reduce feed rate and use roll on strategy. When different tool dimeters are used there are different cutting conditions which is influenced by the principal cutting edge angle and it influence cutting tool life and tool wear character. This study is focused on the influence of the three different cutter diameter on the cutting tool life when the Inconel 718 is machined. For the tests different cutter diameters with same rounding cutting inserts are used. The trajectory of the movement are simulated for all diameters by the 3D view and on the base of it the real cutting conditions are calculate and setup for the practical experiment. During the tests, the cutting forces are monitored as well as cutting inserts tool wear (2D visualization and 3D visualization). For the comparing of the tool wear character the difference analyses is used and 2D cuts are made for the evaluation of the general tool wear parameters.
\end{abstract}

Keywords: Milling cutter; Tool diameter; Cutting tool life; Inconel 718; Tool wear

\section{Introduction}

Inconel 718 belongs to a group of difficult-to-machine materials. It offers excellent strength at low and high temperatures, corrosion resistance under demanding conditions and low thermal diffusivity. Therefore, it found use in components that operate under extreme loads in heavy-duty applications. Their examples include parts of combustion turbines, thin-walled aircraft components and parts of space shuttles. Its use in production has called for operation sequences which deliver optimum machining performance. Today, conventional machining of Inconel 718 poses a major difficulty in terms of the process economy. The motivation for this study arose from a search for appropriate machining parameters and from efforts to improve machining productivity of this material. For this purpose, information from worldwide databases was gathered. One of the key factors which govern the economy of cutting nickel alloys is the short durability of cutting tools. Numerous studies have been devoted to this aspect. One of them explored the effects of cutting conditions on tool durability. This study found that the dominant type of wear, regardless of cutting conditions, is the built-up edge which eventually leads to chipping of the cutting part of tool. Furthermore, if an inadequate thin film is 
chosen, the intensity of abrasive wear increases very rapidly. [1] This was confirmed by another study. Its authors were dealing with thin film optimization - which can improve overall durability by several per cent. [2] Cutting conditions affect the type and progress of wear very strongly. This issue was explored by authors of [3]. They monitored changes in the wear type depending on cutting speed, feed and cutting depth. They also correlated these aspects with the machined surface quality and monitored the impact of cutting conditions on changes in the material. It is clear that the greatest impact on durability results from changes in the cutting speed, whereas the quality of machined surface is dictated predominantly by changes in feed. Surface integrity in machining of Inconel 718 is the topic of additional studies. One of them [4] mapped defects in the machined surface in relation to the occurrence of wear and built-up edge. Similar results were reported by authors of [5] who correlated them with cryogenic machining. They found that better outcome is obtained with standard cooling. Another study describes industrial machining of turbine blades of this material. Its authors dealt with optimizing the production process while taking into account the occurrence of wear and maintaining the quality of machined surface and its accuracy. [6] They found that the profile shape affected the resultant roughness and accuracy. They used the findings in another publication [7] in which they added investigation of the influence of wear on roughness at various points along the turbine blade profile during machining with a ball mill. The dominant factor in the resultant quality of surface was the location of engagement of the ball mill along the blade profile. It was confirmed that roughness becomes less favourable with decreasing engagement radius, and therefore with decreasing cutting speed. The similar results gave authors which were focused on the turning with the different cutting tool radius [8]. One of the many available options for productive machining of Inconel 718 is High Speed Machining (HSC). Yet, the cutting part wear is a major factor in this process as well. This was the subject of the detailed study [9] which monitored the amount of wear of a cemented carbide cutting part vs. the cutting speed used. The results suggested that the amount of wear increased with cutting speed. The material, which is very appropriate for HSC machining of Inconel 718, is cubic boron nitride (PCB). The study [10] found that in this case, too, wear is governed by the cutting speed but also by the microstructure of the work and by the exact chemical composition of the cutting part's material. A very novel method of controlling the durability of CBN tools involves creating a defined surface texture on the cutting part of the tool. This is the focus of the study [11] which describes the texture shapes, cutting conditions and the benefits of this approach. Since Inconel 718 is difficult to machine, there are other studies which seek productive cutting and machining methods for this material. Authors of [12] explored the economy and environmental impacts of various waterjet cutting processes. The last article [13] deal with possibilities of evaluation oscillation absorption and damping factor is increased due to the large dissipative forces resulting from the resistance of the tool holder material that has texture with different metal deformation conditioned orientations. Clearly, this field offers many options for optimizing the machining process - and any improvement in tool durability counts.

On the base of these studies, the article will be deal with influence of the milling cutter diameter on the cutting tool life when machining Inconel 718. The main aim is to describe how the different cutting tool diameter influence the tool life, which is depending on side and rear plane and connected angels. For the evaluation, the different engaging conditions were used with the constant machining conditions.

\section{Experiment}

The objective of this experiment was to identify the relationship between the diameter and durability of a milling cutter. The diameters under test included 50, 100 and 125 (121) mm. The limit flank wear was set at $0.15 \mathrm{~mm}$. During analysis of the static geometry and conversion into the kinematic geometry, it was found that the geometric set-up of these tools would differ. They were therefore adjusted to ensure that the resulting kinematic geometries of engagement were identical for all tool variants. Circular cemented-carbide exchangeable cutting inserts (below referred to as VBD) were used which had a thin film which had been specially developed for Inconel 718. No defects in this film were found upon a thorough inspection. All experimental runs were carried out at constant cutting speed $\mathrm{v}_{\mathrm{c}}=40 \mathrm{~m} / \mathrm{min}$, feed per tooth $\mathrm{f}_{\mathrm{z}}=0.2 \mathrm{~mm}$ and depth of cut $\mathrm{a}_{\mathrm{p}}=2 \mathrm{~mm}$. A constant width of engagement was chosen for the first variant, $\mathrm{a}_{\mathrm{e}}=30 \% \mathrm{D}$ of the milling cutter, as recommended by the manufacturer.

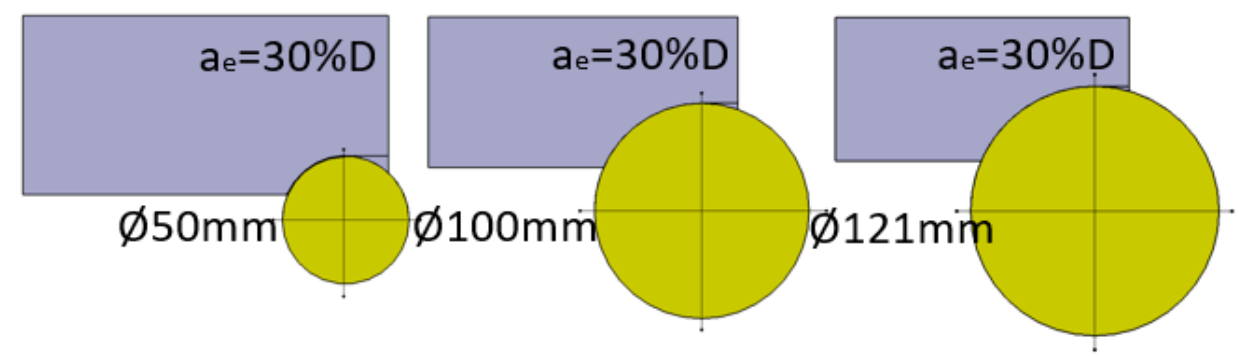

Fig. 1. Visualization of engagement conditions

In this case, the other parameters were set as follows: 


\begin{tabular}{|c|c|c|c|}
\hline & D= 50 mm & $\mathbf{D = 1 0 0 ~} \mathbf{~ m m}$ & $\mathbf{D = 1 2 1 . 7 6}$ \\
\hline $\mathrm{vc} \mathrm{[m/min}]$ & 40 & 40 & 40 \\
\hline $\mathrm{vf}[\mathrm{m} / \mathrm{min}]$ & 51 & 25 & 21 \\
\hline ap [mm] & 2 & 2 & 2 \\
\hline ae [mm] & 15 & 30 & 36.53 \\
\hline fz [mm] & 0.2 & 0.2 & 0.2 \\
\hline n [-] & 255 & 127 & 105 \\
\hline $\begin{array}{c}\text { Arc of engagement } \\
\Psi\left[{ }^{\circ}\right]\end{array}$ & 66.42 & 66.42 & 66.42 \\
\hline Q [cm3/min] & 1.53 & 1.53 & 1.53 \\
\hline
\end{tabular}

Table 1. Cutting conditions at constant ae

Only a single VBD was employed in the experiment in each case, which can lead to lower durability of the tool due to instability which occurs as a single VBD enters the work. To verify the findings, the experiment will be repeated with a fully-fitted milling head.

The entry into the workpiece was modified by pre-milling the work at $30 \% \mathrm{D}$ for the tool diameter. Therefore, the VBD was not affected by the entry and exit variations, as illustrated in Fig. 2.

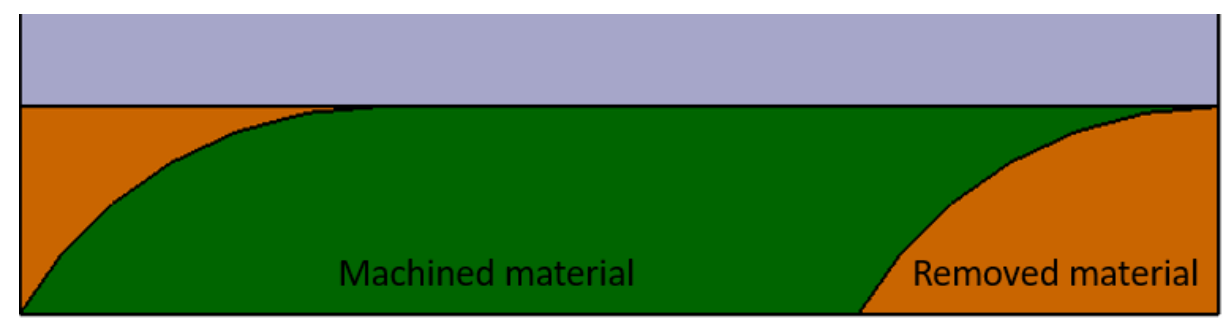

Fig. 2. Visualization of the pre-milled workpiece

It is important to check the material prior to testing: the chemical composition, microstructure, hardness and other mechanical properties if relevant. With regard to machinability and the effects on tool durability, the important aspects include the chemical composition, heat treatment history and the resultant microstructure and hardness.

\begin{tabular}{|c|c|c|c|c|c|c|c|c|c|c|c|c|c|c|c|}
\hline C & $\overline{M n}$ & $\overline{\mathbf{S i}}$ & $\bar{P}$ & S & $\mathrm{Ca}$ & $\mathrm{Cr}$ & Al & $\mathrm{Cu}$ & Mo & $\mathbf{N i}$ & $\mathbf{N}$ & $\mathrm{Ti}$ & $\mathrm{Fe}$ & $\mathrm{Nb}$ & $\overline{C o}$ \\
\hline 0,017 & 0,10 & 0,07 & 0,008 & 0,0005 & $<0,0003$ & 18,23 & 0,51 & 0,04 & 2,98 & 53,3 & 0,006 & 0,98 & 18,22 & 5,09 & 0,31 \\
\hline & & & & \multirow{2}{*}{\multicolumn{12}{|c|}{ Other }} \\
\hline B & $\mathrm{Pb}$ & $\mathrm{Ta}$ & 0 & & & & & & & & & & & & \\
\hline$\overline{0,0024}$ & $<0,0003$ & $<0,020$ & $<0,00003$ & $q=0$ & 0010 & $S n=0, c$ & 011 ; & $\mathrm{e}=<0$ & & & & & & & \\
\hline
\end{tabular}

Fig. 3. Chemical composition of workpiece

To check the homogeneity of microstructure of the workpiece, samples were taken from its surface, from a location $20 \mathrm{~mm}$ below the surface and from the workpiece centre.
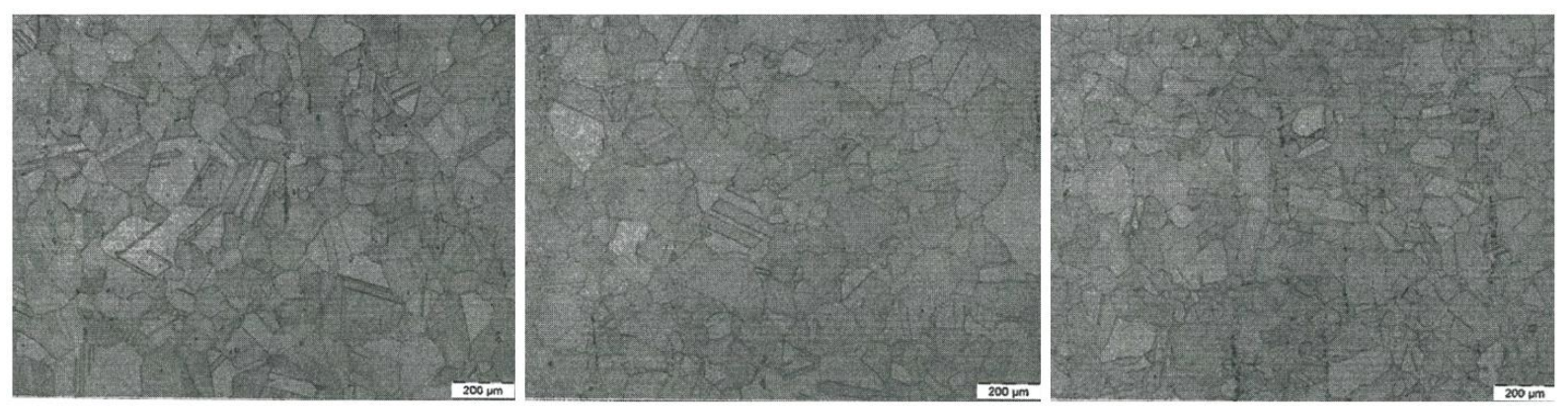

Fig. 4. Microstructure of the Inconel 718 workpiece (from left: surface, $20 \mathrm{~mm}$ below the surface, centre)

The images show that the grain shapes and sizes depend on the location within the workpiece. On the other hand, this is a common occurrence in the industrial practice. Therefore, no steps were taken to modify the microstructure. Instead, hardness was measured in these locations. Its values were in the range of 34-39 HRC, depending on the location. 
Machining was carried out in a 5-axis milling centre. The workpiece was clamped in a hydraulic vice. In order to ensure that identical material (microstructure) is removed by tools of each diameter, they were all applied to a single layer of the workpiece in each case. The effect of the microstructure variation was thus eliminated.

The results are plotted in Graph 1.

$$
\mathrm{ae}=30 \% \mathrm{D}
$$

25

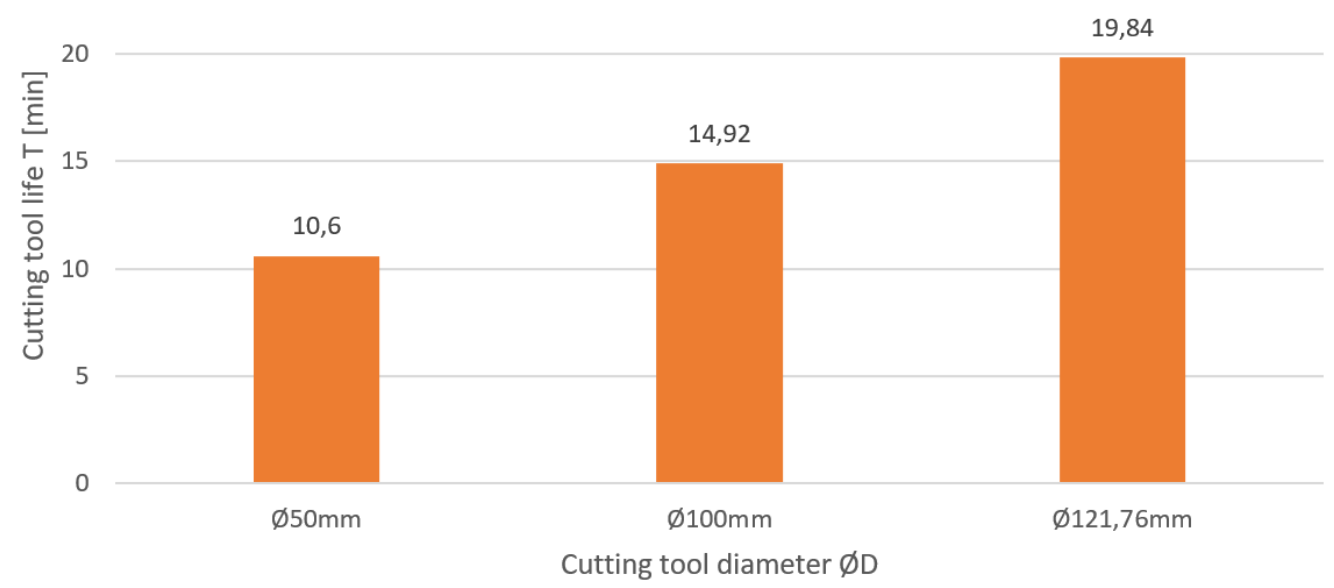

Graph 1. Tool durability vs. tool diameter in machining a pre-milled workpiece

The graph indicates that durability increases with the tool diameter. Constant $a_{e}$ means that the arc of engagement is the same for all tools, although the width of engagement increases with the tool diameter. Hence, the smaller is the tool diameter, the more entries the tool must complete, which means that it sustains more impacts. Upon conversion per diameter basis, the following results were obtained:

\begin{tabular}{|c|c|c|c|}
\hline & $\emptyset 50 \mathrm{~mm}$ & $\emptyset 100 \mathrm{~mm}$ & $\emptyset 121.76 \mathrm{~mm}$ \\
\hline Alternative No. 2 & 2700 & 2375 & 2075 \\
\hline
\end{tabular}

Table 2. Number of impacts of tool on the workpiece at the end of durability

One can therefore assume that with the number of impacts on the workpiece, the tool wear will increase more rapidly, reaching the limit value of $0.15 \mathrm{~mm}$ much earlier, as reflected in the durability.

For further comparison and verification, an experiment was carried out under identical cutting conditions on a workpiece which had not been pre-milled.

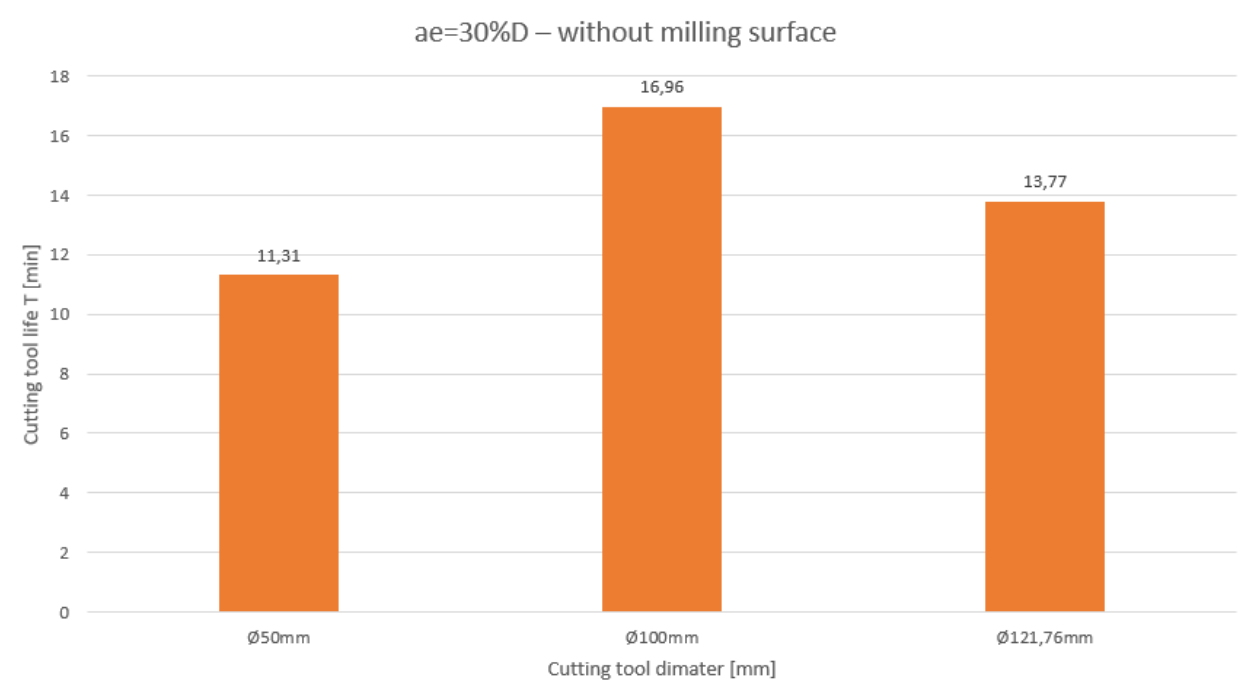

Graph 2. Tool durability vs. tool diameter in machining a non-pre-milled workpiece 
Durability was higher than with the pre-milled workpiece but it no longer increased with the tool diameter. This setup will therefore be analysed further because the results represent mean values from repeated runs.

The last experiment involved a comparison with a milling head with all VBDs fitted, under identical conditions. While the tools with $100 \mathrm{~mm}$ and $121 \mathrm{~mm}$ diameters had the same numbers of cutting inserts (VBDs) and an identical arc of engagement, the stability condition was fulfilled, i.e. more than one VBD being engaged at a time. For these reasons, only these two diameters were used for the comparison.
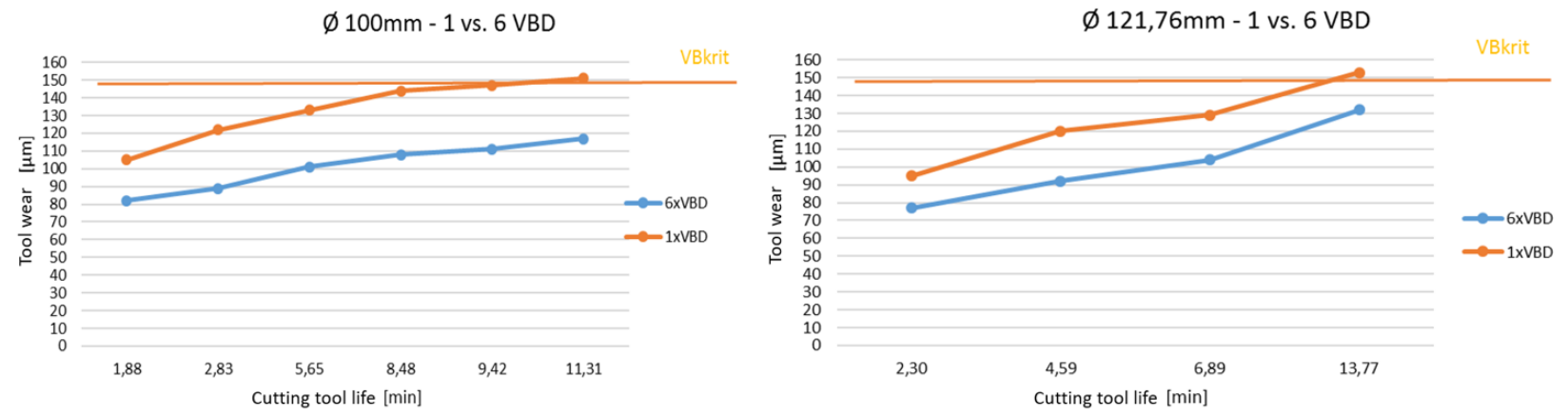

Graph 3. Effects of stability on tool durability in cutting with a single and multiple VBDs

The graphs clearly show that the use of a single VBD in the experiment affects the actual durability of the tool. It is mainly due to increased instability, as the tool suffers stronger vibration than a tool on which more than 1 VBD is engaged and which remains stable throughout the cutting operation. On the other hand, this has no impact on the plausibility of the results. Machining with a single VBD led to uniform abrasive wear, same as with the milling head with all positions occupied. No significant differences were found. The wear profile is shown in Fig. 5.

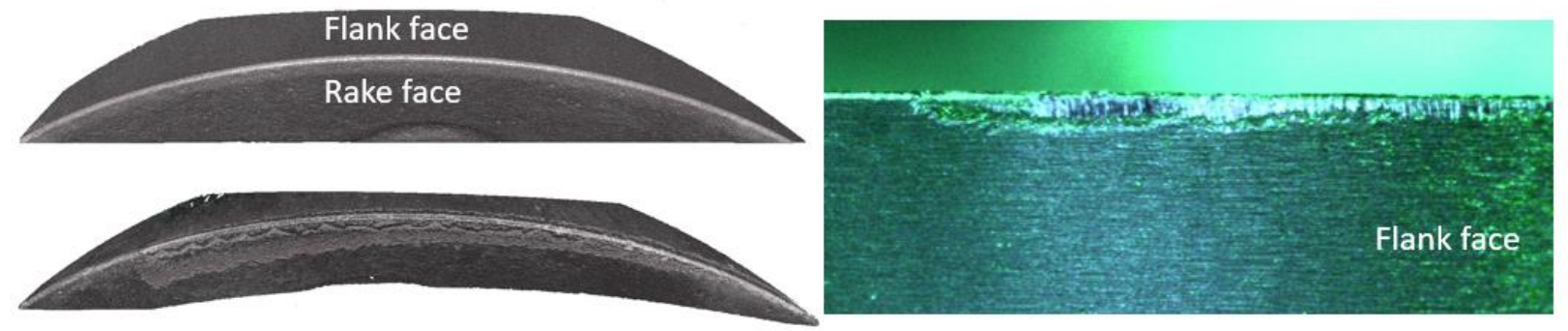

Fig. 5. Visualization of wear (left: 3D-scanned image of wear; right: 2D optical micrograph)

\section{Conclusion}

The results show the effects of the tool diameter and cutting conditions on tool durability. While the basic principle for defining cutting conditions was observed, i.e. a constant width of engagement, it was found that durability increases with the tool diameter. This may be of major importance in selecting the machining strategy and while considering the diameter for a particular size of machined surface. With Inconel 718, it is appropriate to use multiple tools of different diameters, instead of choosing a single diameter for removing material without the need for tool replacement. In many cases, this variant may prove very costly due to lower durability, and therefore the need for more frequent replacement of VBDs. These experiments also showed the effects of the stability of the cutting process on tool durability. When a single VBD is used, durability decreases. This means that in the choice of engagement conditions made in the industrial practice, it is important to ensure that more than a single point of the tool is engaged at a time. This may prove difficult or even unfeasible to meet with tools of small diameters. The above analyses provide underlying knowledge for future investigations which will focus on various engagement conditions.

\section{Acknowledgments}

This paper was supported by the programme of applied research, experimental development and innovation GAMA, No. TG02010011 - Support of UWB commercial opportunities. 


\section{References}

[1] H. Abdul, J. A. Ghani, H. Che, and M. S. Kasim. (2016). Effect of cutting speed on the carbide cutting tool in milling Inconel 718 alloy, J. Mater. Res., Vol. 31, No. 13, pp. 1885-1892, DOI: 10.1557/jmr.2015.380.

[2] M. Sortino, S. Belfio, G. Totis, E. Kuljanic, and G. Fadelli. (2015). Innovative tool coatings for increasing tool life in milling Nickel-coated Nickel-Silver alloy, Energy Procedia, Vol. 100, pp. 946-952. DOI: $10.1016 /$ j.proeng.2015.01.453

[3] M. A. Xavior, M. Manohar, P. Jeyapandiarajan, and P. M. Madhukar. (2017). Tool Wear Assessment During Machining of Inconel 718, Procedia Eng., Vol. 174, pp. 1000-1008, DOI: 10.1016/j.proeng.2017.01.252.

[4] C. Liu, C. Ren, G. Wang, Y. Yang, and L. Zhang. (2015). Study on surface defects in milling Inconel 718 super alloy, J. Mech. Sci. Technol., Vol. 29, No. 4, pp. 1723-1730, DOI: 10.1007/s12206-015-0345-1.

[5] A. Iturbe, E. Hormaetxe, A. Garay, and P. J. Arrazola. (2016). Surface Integrity Analysis when Machining Inconel 718 with Conventional and Cryogenic Cooling, Procedia CIRP, Vol. 45, pp. 67-70, DOI: 10.1016/j.procir.2016.02.095.

[6] J. Kyncl, L. Beránek, K. Kolarík, and Z. Pala. (2014). The research of the surface profile after profiling of inconel 738LC, Procedia Engineering, Vol. 69, pp. 974-979. DOI: 0.1016/j.proeng.2014.03.078.

[7] J. Kyncl and A. Molotovnik. (2015). The research of the surface profile after profiling of superalloys, Energy Procedia, Vol. 100, pp. 853-860. DOI: 10.1016/j.proeng.2015.01.441.

[8] N. Qehaja, K. Jakupi, A. Bunjaku, M. Bruçi, a H. Osmani. (2015). Effect of Machining Parameters and Machining Time on Surface Roughness in Dry Turning Process, Procedia Eng., roč. 100, s. 135-140, DOI: 10.1016/j.proeng.2015.01.351

[9] D. M. D’Addona, S. J. Raykar, and M. M. Narke. (2017). High Speed Machining of Inconel 718: Tool Wear and Surface Roughness Analysis, Procedia CIRP, Vol. 62, pp. 269-274, DOI: 10.1016/j.procir.2017.03.004.

[10] H. Tanaka, T. Sugihara, and T. Enomoto. (2016). High Speed Machining of Inconel 718 Focusing on Wear Behaviors of PCBN Cutting Tool, Procedia CIRP, Vol. 46, pp. 545-548, DOI: 10.1016/j.procir.2016.03.120.

[11] T. Sugihara, H. Tanaka, and T. Enomoto. (2017). Development of Novel CBN Cutting Tool for High Speed Machining of Inconel 718 Focusing on Coolant Behaviors, Procedia Manuf., Vol. 10, pp. 436-442, DOI: 10.1016/j.promfg.2017.07.021.

[12] G. S. Kadam and R. S. Pawade. (2017). Surface integrity and sustainability assessment in high-speed machining of Inconel 718 - An eco-friendly green approach, J. Clean. Prod., Vol. 147, pp. 273-283, DOI: 10.1016/j.jclepro.2017.01.104.

[13] J. Olt a V. V. Maksarov. (2015). Development of chatter-resistant system of cutting tool, Annals of DAAAM and Proceedings of the International DAAAM Symposium, 2015 p. 223-226. DOI: 10.2507/26th.daaam.proceedings.031 